\title{
USO DE NITROGÊNIO NO SISTEMA DE PRODUÇÃO DE SOJA SOBRE PALHADA DE CANA-DE-AÇÚÇAR
}

ISSUE DOI: $10.3738 /$ nucleus.v0i0.909

BORGES, Wander Luis Barbosa ${ }^{1}$;

MATEUS, Gustavo Pavan';

FREITAS, Rogério Soares de ${ }^{1}$; TOKUDA, Flávio Sueo ${ }^{3}$;

HIPÓLITO, Jorge Luiz

TOMAZINI, Nicola Roberto

CAZENTINI FILHO, Gerson ${ }^{6}$;

GASPARINO, Adriano Custódio ${ }^{3}$

\begin{abstract}
RESUMO: Considerando-se que a partir de 2014 não serão mais permitidas as queimadas nos canaviais paulistas, os sojicultores que arrendam estas áreas, deverão se adaptar ao sistema de semeadura direta a fim de aproveitar os benefícios agronômicos que o palhiço de cana proporciona. O trabalho foi desenvolvido em Araçatuba, SP, durante a safra de 2011/12, e em Araçatuba, SP e Américo de Campos, SP, na safra 2012/13, e teve por objetivo avaliar a influência do nitrogênio na produtividade de diferentes cultivares de soja, cultivadas no sistema de semeadura direta sobre palhada de cana-de-açúcar, e a influência sobre a degradação da palhada. Foi utilizado o delineamento em blocos casualizados em esquema de faixas com parcelas subdivididas e três repetições. Na safra 2011/12 foi utilizado um esquema fatorial 5 x 2, com cinco cultivares de soja: P 98Y11 RR; CD 219 RR; M-Soy 7908 RR; BRS Valiosa RR e SYN 9078 RR, e duas doses de nitrogênio: 0 e $45 \mathrm{~kg} \mathrm{ha}^{-1}$, na forma de ureia. Na safra 2012/13, o estudo foi realizado na cultivar M-Soy 7908 RR, em Araçatuba, SP e na cultivar SYN 9078 RR, em Américo de Campos, SP, utilizando-se quatro tratamentos (doses de nitrogênio): $0,30,45$ e $60 \mathrm{~kg} \mathrm{ha}^{-1}$, na forma de nitrato de amônio (30 e 60 $\left.\mathrm{kg} \mathrm{ha}^{-1}\right)$ e ureia $\left(45 \mathrm{~kg} \mathrm{ha}^{-1}\right)$. Constatou-se que a utilização de ureia e de nitrato de amônio não influenciou a decomposição da palhada de cana-de-açúcar e não propiciaram incrementos significativos na produtividade de grãos das cultivares de soja avaliadas.
\end{abstract}

Palavras-chave: Glycine max (L.) Merrill, Saccharum spp., Fitomassa, Cultivares.

\section{USE OF NITROGEN IN THE SOYBEAN PRODUCTION SYSTEM ON STRAW SUGARCANE}

SUMMARY: Considering that from 2014 will no longer be allowed fires in São Paulo sugarcane, soybean growers who lease these areas should adapt to the no-tillage system in order to enjoy the agronomic benefits that the straw sugarcane provides. The study was conducted in Araçatuba, SP, during crop year 2011/12, and Araçatuba, SP, Brazil and Américo de Campos, SP, Brazil in 2012/13 and aimed to evaluate the influence of nitrogen on the yield of different cultivars soybean grown no-till on straw sugarcane, and the influence on the degradation of straw. We used a randomized block design in split-bands split plot with three replications. In the crop year 2011/12 we used a 5 x 2 factorial design, with five soybean cultivars: P 98Y11 RR, RR CD 219, M-Soy 7908 RR, BRS Valiosa and RR SYN $9078 \mathrm{RR}$, and two nitrogen levels: 0 and $45 \mathrm{~kg} \mathrm{ha}^{-1}$ in the form of urea. In the crop year 2012/13, the study was conducted on the cultivar M-Soy 7908 RR in Araçatuba, SP, Brazil and on the cultivar SYN 9078 RR in Américo de Campos, SP, Brazil using four treatments (nitrogen): $0,30,45$ and $60 \mathrm{~kg} \mathrm{ha}^{-1}$, in the form of ammonium nitrate (30 and $\left.60 \mathrm{~kg} \mathrm{ha}^{-1}\right)$ and urea $\left(45 \mathrm{~kg} \mathrm{ha}^{-1}\right)$. It was found that the use of urea and ammonium nitrate did not influence the straw decomposition of cane sugar and did not promote significant increases in grain yield soybean of the cultivars evaluated.

Keywords: Glycine max (L.) Merrill, Saccharum spp., Phytomass, Cultivars.

\footnotetext{
${ }^{1}$ Pesquisador Científico, Dr. - APTA - PRDTA Noroeste Paulista, Votuporanga, SP;

${ }^{2}$ Pesquisador Científico, Dr. - APTA - PRDTA Extremo Oeste, Andradina, SP;

${ }^{3}$ Assistente Agropecuário - CATI - EDR Votuporanga, Votuporanga, SP;

${ }^{4}$ Assistente Agropecuário - CATI - EDR Araçatuba, Araçatuba, SP;

${ }^{5}$ Assistente Agropecuário - CATI - DSMM - NPS, Araçatuba, SP;

${ }^{6}$ Assistente Agropecuário - CATI - DSMM - NPS, Fernandópolis, SP.
} 


\section{INTRODUÇÃO}

Considerando-se que a partir de 2014 não serão mais permitidas as queimadas nos canaviais paulistas, os sojicultores que arrendam estas áreas, deverão se adaptar ao sistema de semeadura direta a fim de aproveitar os benefícios agronômicos que o palhiço de cana (em média $15000 \mathrm{~kg} \mathrm{ha}^{-1}$ de matéria seca) proporciona (BOLONHEZI et al., 2008).

A quantidade dos resíduos (folhas e palmitos) resultantes da colheita mecanizada de cana-crua depende de uma série de condições intrínsecas à máquina colhedora e outras relativas à planta ou à condição de manejo da mesma (ABRAMO FILHO et al., 1993).

Considerando resultados obtidos por vários autores brasileiros, Ripoli et al. (1990) obtiveram uma estimativa de que um hectare de cana-de-açúcar com rendimento agrícola de $70000 \mathrm{~kg} \mathrm{ha}^{-1}$, cortada sem queima prévia resultariam em $7000 \mathrm{~kg} \mathrm{ha}^{-1}$ de palha. No entanto, Trivelin et al. (1996) afirmaram que a quantidade de palha em canaviais colhidos sem queima, varia de 10000 a $30000 \mathrm{~kg} \mathrm{ha}^{-1}$.

Amado, Mielniczuk e Aita (2002) enfatizaram que resíduos de gramíneas, quando adicionados à superfície do solo, apresentam decomposição mais lenta, quando comparado com leguminosas e crucíferas, e sugeriram que isto ocorre devido à alta relação $\mathrm{C} / \mathrm{N}$ das gramíneas e em muitos casos a reduzida disponibilidade de $\mathrm{N}$ mineral do solo.

Apesar dos grandes benefícios ambientais, operacionais e econômicos da colheita mecanizada sem queima, a deposição e a manutenção de palha sobre a superfície do solo trouxeram algumas dificuldades no processo produtivo, que gradativamente está sendo superado pela pesquisa (KUVA, 2006). Entre essas dificuldades pode ser citada a baixa taxa líquida de mineralização de nitrogênio (TRIVELIN et al., 1995).

Segundo Mascarenhas et al. (1978), no sistema de semeadura direta ocorre uma maior deficiência de nitrogênio, principalmente, quando se faz plantio de gramíneas, em decorrência do movimento descendente da água favorecer a maior lixiviação de nitratos, já que a não movimentação do solo, nesse sistema de plantio, evita a quebra da capilaridade, e prevalecendo tais condições, há a necessidade de aumento da adubação nitrogenada, principalmente em rotação com cana-de-açúcar.

O presente trabalho teve por objetivo avaliar a influência do nitrogênio na produtividade de diferentes cultivares de soja, cultivadas no sistema de semeadura direta sobre palhada de cana-de-açúcar, e a influência sobre a degradação da palhada.

\section{MATERIAL E MÉTODOS}

O trabalho foi desenvolvido em Araçatuba, SP, na safra 2011/12, e em Araçatuba, SP e Américo de Campo, SP, na safra 2012/13, com a semeadura da soja realizada mecanicamente, com semeadoras de grãos, em sistema de semeadura direta sobre a palhada da cana-de-açúcar colhida sem queima (cana crua), na renovação do canavial.

A semeadura da soja foi realizada no dia 28 de novembro de 2011, na safra 2011/12, e no dia 13 de novembro de 2012, em Araçatuba, SP, e no dia 20 de dezembro de 2012, em Américo de Campos, SP, na safra 2012/13.

Foi utilizado o delineamento em blocos casualizados em esquema de faixas com parcelas subdivididas e três repetições, com parcelas de $50 \mathrm{~m}^{2}$ de área cada, no primeiro ano, e $100 \mathrm{~m}^{2}$, no segundo ano.

Na safra 2011/12 foi utilizado um esquema fatorial 5 x 2, com cinco cultivares de soja: P 98 Y11 RR; CD 219 RR; M-Soy 7908 RR; BRS Valiosa RR e SYN 9078 RR, e duas doses de nitrogênio: 0 e 45 $\mathrm{kg} \mathrm{ha}^{-1}$, na forma de ureia, sendo o nitrogênio aplicado em metade da área de cada parcela $\left(25 \mathrm{~m}^{2}\right)$. 
Utilizou-se também um tratamento padrão, com $0 \mathrm{~kg} \mathrm{ha}^{-1}$ de nitrogênio. A ureia foi diluída em água ( $250 \mathrm{~g}$ $\mathrm{L}^{-1}$ ) e a solução nitrogenada foi pulverizada sobre a palhada da cana-de-açúcar, logo após a semeadura da cultura da soja.

Na safra 2012/13, o estudo foi realizado na cultivar M-Soy 7908 RR, em Araçatuba, SP e na cultivar SYN 9078 RR, em Américo de Campos, SP, utilizando-se quatro tratamentos (doses de nitrogênio): 0, 30, 45 e $60 \mathrm{~kg} \mathrm{ha}^{-1}$, na forma de nitrato de amônio (30 e $60 \mathrm{~kg} \mathrm{ha}^{-1}$ ) e ureia $\left(45 \mathrm{~kg} \mathrm{ha}^{-1}\right)$. Utilizou-se também um tratamento padrão, com $0 \mathrm{~kg} \mathrm{ha}^{-1}$ de nitrogênio. As parcelas foram divididas em quatro subparcelas (tratamentos), com área de $25 \mathrm{~m}^{2}$, cada. O nitrato foi distribuído a lanço sobre a palhada de cana-de-açúcar e a ureia foi diluída em água $\left(250 \mathrm{~g} \mathrm{~L}^{-1}\right)$ e a solução nitrogenada foi pulverizada sobre a palhada da cana-de-açúcar. O nitrogênio foi aplicado logo após a semeadura da cultura da soja.

As características químicas e físicas do solo e os tratos culturais da cultura da soja utilizados neste estudo, foram os mesmos do estudo que originou o artigo "Desempenho de cultivares de soja em palhada de cana-de-açúcar no Noroeste Paulista", apresentado nesta edição especial da Revista Nucleus, sendo os dois estudos desenvolvidos paralelamente nos mesmos locais, nos dois anos de estudo.

A avaliação de fitomassa seca da palhada da cultura da cana-de-açúcar foi realizada nas parcelas com e sem aplicação de $\mathrm{N}$, retirando-se três amostras por parcela de $0,25 \mathrm{~m}^{2}$ cada, no momento da semeadura e na colheita da soja, nos dois anos de estudo, e também aos 60 e 75 dias após a semeadura (DAS) em Araçatuba, SP e Américo de Campos, SP, respectivamente, na safra 2012/13.

Os parâmetros avaliados na cultura da soja, nos dois anos de estudo, foram: altura de inserção da primeira vagem, altura de plantas e número de vagens por planta, amostrando-se cinco plantas de cada parcela e o estande final ha ${ }^{-1}$ e a produtividade de grãos ha ${ }^{-1}$, amostrando-se $10 \mathrm{~m}$ nas duas linhas centrais de cada parcela. Na safra 2012/13, não foi avaliada o número de vagens por planta. As avaliações foram realizadas no momento da colheita.

Os dados foram submetidos ao teste $\mathrm{F}$ e realizado o teste de Tukey $(\mathrm{p}<0,05)$, para comparação das médias, com o uso do programa computacional ESTAT, desenvolvido pelo Departamento de Ciências Exatas da FCAV/UNESP/Jaboticabal (Estat, 1997). No primeiro ano de estudo, nos casos em que a interação cultivares x nitrogênio foi significativa, realizou-se o desdobramento dos graus de liberdade para verificação dos efeitos de cultivares dentro de nitrogênio e de nitrogênio dentro de cultivares.

Foram coletados dados mensais de pluviosidade e de temperatura média, em todo o período de execução dos ensaios. Os dados encontram-se nas Figuras 1 e 2. 
Figura 1. Dados de precipitação pluvial (PP) e temperatura média (T), em Araçatuba, SP, no período estudado, outubro de 2011 a março de 2012 e novembro de 2012 a março de 2013. Fonte: CIIAGRO, 2013.
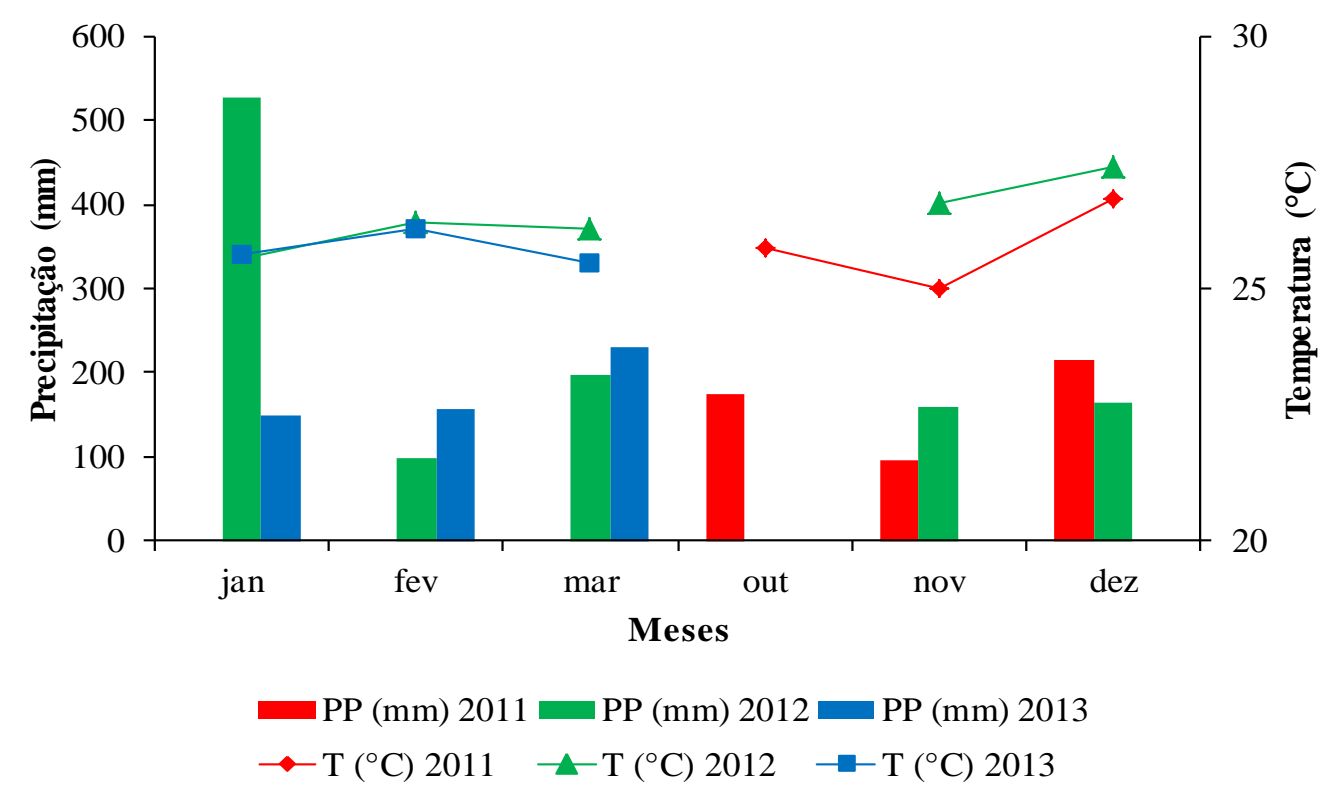

Figura 2. Dados de precipitação pluvial (PP) e temperatura média (T), em Paulo de Faria, SP (estação meteorologia mais próxima a Américo de campos, SP), no período estudado, dezembro de 2012 a março de 2013. Fonte: CIIAGRO, 2013.

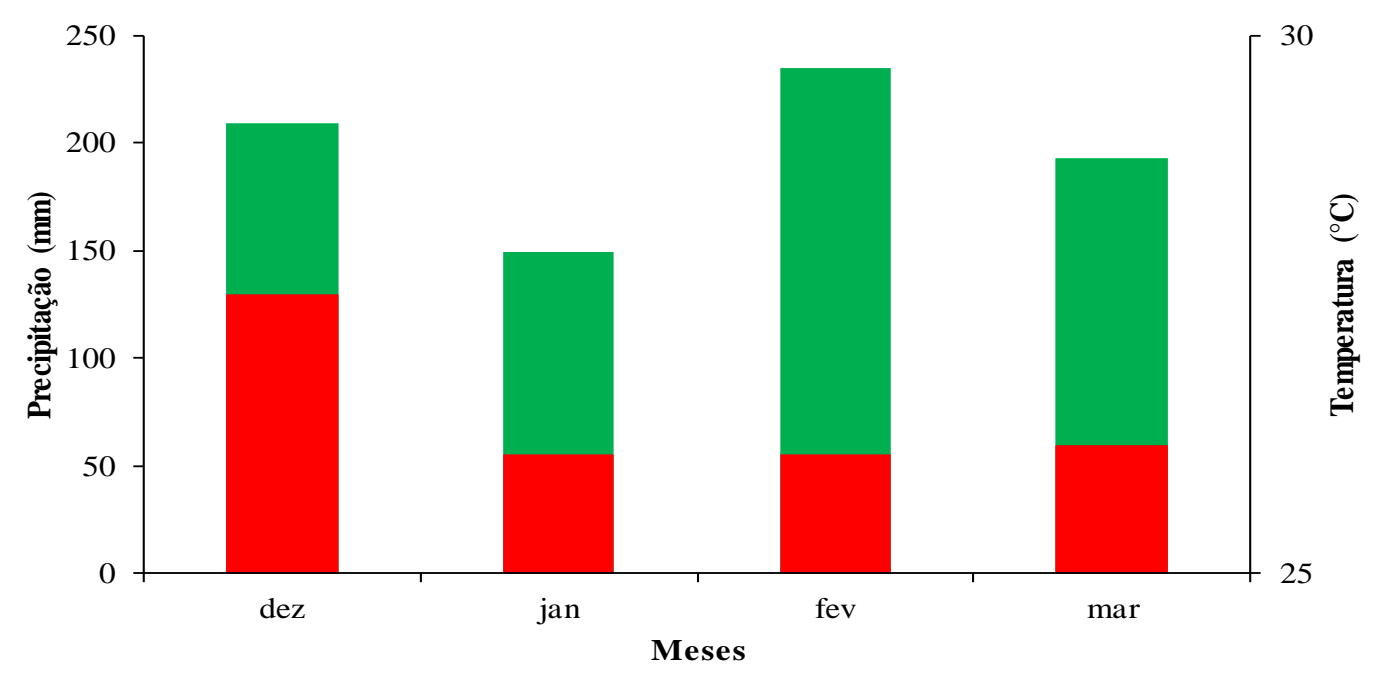

aP (mm) 2012/13 $\square \mathrm{T}\left({ }^{\circ} \mathrm{C}\right) 2012 / 13$

\section{RESULTADOS E DISCUSSÃO}

No primeiro ano de estudo, a quantidade de fitomassa seca da palhada de cana-de-açúcar, no momento da semeadura da soja, foi superior a $17000 \mathrm{~kg} \mathrm{ha}^{-1}$, conforme Tabela 1 , sendo esta quantidade 
superior a encontrada por Timossi e Durigan (2006), que foi de $12800 \mathrm{~kg} \mathrm{ha}^{-1}$, e por Abramo Filho et al. (1993), estimada em cerca de $15000 \mathrm{~kg} \mathrm{ha}^{-1}$.

Tabela 1. Valores médios de fitomassa seca da palha da cultura da cana-de-açúcar, no momento da semeadura e colheita da soja, com e sem aplicação de nitrogênio, Araçatuba, safra 2011/12.

\begin{tabular}{lcc}
\hline Cultivar & Semeadura & Colheita \\
& & \\
\hline P 98Y11 RR & 18020 & 4000 \\
CD 219 RR & 19870 & 4067 \\
M-Soy 7908 RR & 20198 & 3333 \\
BRS Valiosa RR & 17784 & 4067 \\
SYN 9078 RR & 19310 & 3933 \\
\hline DMS (1) & & 2571 \\
\hline DMS (2) & & 1129 \\
\hline CV (\%) & & 37,93
\end{tabular}

(1) Cultivar (2) Nitrogênio

Nos dois anos de estudo e nos dois locais, a utilização do nitrogênio não influenciou a decomposição da palhada, não havendo diferenças dos tratamentos com nitrogênio em relação ao tratamento padrão, sem a utilização de nitrogênio (Tabelas 1, 2 e 3), corroborando com Oliveira et al. (1999), que também não encontraram influência da aplicação de ureia e vinhaça na degradação da lignocelulose e na liberação dos nutrientes da palhada de cana-de-açúcar. Por outro lado, Assis et al. (2003) citaram que a aplicação de nitrogênio sobre a palhada de sorgo, na dose de $30 \mathrm{~kg} \mathrm{ha}^{-1}$, aumenta a taxa de decomposição e diminui a meia vida dessa palhada.

Tabela 2. Valores médios de fitomassa seca da palhada da cultura da cana-de-açúcar, no momento da semeadura, aos 60 dias e na colheita da cultura da soja, Araçatuba, SP, safra 2012/13.

\begin{tabular}{lccc}
\hline $\begin{array}{l}\text { Doses de nitrogênio } \\
\left(\mathrm{kg} \mathrm{ha}^{-1}\right)\end{array}$ & Semeadura & 60 DAS & Colheita \\
\hline 0 & 14450 & 11750 & 7626 \\
30 (Nitrato de amônio) & - & 9100 & 5472 \\
60 (Nitrato de amônio) & - & 7383 & 5833 \\
45 (Ureia) & - & 6667 & 6650 \\
\hline DMS & & 5736 & 3189 \\
\hline $\mathrm{CV}(\%)$ & & 23,24 & 17,62 \\
\hline
\end{tabular}


Tabela 3. Valores médios de fitomassa seca da palhada da cultura da cana-de-açúcar, no momento da semeadura, aos 75 dias e na colheita da cultura da soja, Américo de Campos, SP, safra 2012/13.

\begin{tabular}{lccc}
\hline $\begin{array}{l}\text { Doses de nitrogênio } \\
\left(\mathrm{kg} \mathrm{ha}^{-1}\right)\end{array}$ & Semeadura & 75 DAS & Colheita \\
\hline 0 & 11200 & 7791 & 7517 \\
30 (Nitrato de amônio) & - & 9761 & 8417 \\
60 (Nitrato de amônio) & - & 10015 & 9083 \\
45 (Ureia) & - & 8546 & 8267 \\
\hline DMS & & 2614 & 2407 \\
\hline CV $(\%)$ & & 10,23 & 10,23 \\
\hline
\end{tabular}

A temperatura média superior a $25^{\circ} \mathrm{C}$ e precipitação acumulada no período superior a $750 \mathrm{~mm}$ (Figuras 1 e 2), podem ter favorecido a decomposição mais rápida da palhada, mesmo sem a utilização de nitrogênio. Segundo Oliveira et al. (1999), devido à decomposição de restos culturais ser fortemente influenciada pela temperatura, pode-se inferir que mesmo nos meses mais quentes e de maior disponibilidade hídrica (janeiro a abril e setembro a novembro), a mineralização da palhada não é limitada somente pela sua composição química, pode haver ao menos, o efeito da temperatura na mineralização potencial dessa palhada, uma vez que foi constatado por Stanford et al. (1973) e Katterer et al. (1998) que no intervalo de 5 a $35^{\circ} \mathrm{C}$ a taxa de mineralização dobra a cada $10^{\circ} \mathrm{C}$ de aumento na temperatura.

No primeiro ano de estudo, a utilização de nitrogênio influenciou o número de vagens por planta, com aumento do número de vagens para a cultivar P 98Y11 RR e redução para as cultivares CD 219 RR e BRS Valiosa RR, e também a produtividade de grãos, com redução da produtividade para a cultivar MSoy 7908 RR, conforme Tabelas 4, 5 e 6. Diversos trabalhos com a utilização de nitrogênio na cultura da soja foram realizados, no entanto há divergências em relação a ganhos de produtividade, sendo que Santos et al. (2000) encontraram aumento de 10,9\% com a maior dose (120 kg ha $\left.{ }^{-1}\right)$, e Lamond e Wesley (2001) obtiveram aumento de $11 \%$ (471 $\left.\mathrm{kg} \mathrm{ha}^{-1}\right)$ com a adubação nitrogenada tardia, citando ser esta prática economicamente viável para produtores de soja irrigada altamente produtiva. Por outro lado, Aratani et al. (2008) não verificaram aumento de produtividade em relação ao tratamento sem $\mathrm{N}$, independente da época de aplicação e Crispino et al. (2001) não encontraram incrementos significativos com a dose inicial de 30 $\mathrm{kg}$ de $\mathrm{N} \mathrm{ha}^{-1}$.

Tabela 4. Valores médios da altura de inserção da primeira vagem, altura de plantas, estande final, número de vagens por planta e produtividade de grãos de diferentes cultivares de soja, Araçatuba, SP, safra 2011/12.

(Continua)

\begin{tabular}{|c|c|c|c|c|c|}
\hline & Altura de & Altura de & Estande & Número de & Produtividade \\
\hline Cultivar & inserção $(\mathrm{cm})$ & plantas $(\mathrm{cm})$ & final $\mathrm{ha}^{-1^{*}}$ & $\begin{array}{l}\text { Vagens } \\
\text { planta }^{-1}\end{array}$ & $\left(\mathrm{~kg} \mathrm{ha}^{-1}\right)$ \\
\hline M-Soy 7908 RR & 0,23 & 0,89 & 270368 & 88 & 2965 \\
\hline P 98Y11 RR & 0,22 & 1,01 & 255553 & 82 & 2613 \\
\hline BRS Valiosa RR & 0,20 & 0,88 & 248146 & 77 & 4290 \\
\hline CD $219 R R$ & 0,20 & 1,00 & 230862 & 87 & 2635 \\
\hline
\end{tabular}

Nucleus, Edição Especial, 2013 
Tabela 4. Valores médios da altura de inserção da primeira vagem, altura de plantas, estande final, número de vagens por planta e produtividade de grãos de diferentes cultivares de soja, Araçatuba, SP, safra 2011/12.

(Conclusão)

\begin{tabular}{lccccc} 
SYN 9078 RR & 0,23 & 1,26 & 248146 & 73 & 2585 \\
\hline DMS (1) & 7,35 & 13,93 & 32 & 158,93 \\
\hline DMS (2) & 3,23 & 6,11 & 14 & 69,75 \\
\hline CV $(\%)$ & 19,75 & 7,93 & 22 & 16,58 \\
\hline
\end{tabular}

* Não se comparou as médias por variarem de acordo com a recomendação do detentor da cultivar.
(1) Cultivar
(2) Nitrogênio

Tabela 5. Desdobramento da interação entre cultivares e nitrogênio no número de vagens por planta da cultura da soja, Araçatuba, SP, safra 2011/12.

\begin{tabular}{lcc}
\hline Cultivar & sem N & com N \\
\hline P 98Y11 RR & 72 Bab & 103 A \\
CD 219 RR & 100 Aab & 64 B \\
M-Soy 7908 RR & 64 b & 90 \\
BRS Valiosa RR & 110 Aa & 64 B \\
SYN 9078 RR & 86 ab & 60
\end{tabular}

\begin{tabular}{ll}
\hline DMS (1) & 44,66 \\
\hline DMS (2) & 30,99
\end{tabular}

Médias seguidas de mesma letra minúscula na coluna e maiúscula na linha não diferem entre si pelo teste de Tukey a $5 \%$ de probabilidade de erro.

(1) Nitrogênio dentro de cultivar $\quad$ (2) Cultivar dentro de nitrogênio

Tabela 6. Desdobramento da interação entre cultivares e nitrogênio na produtividade de grãos da cultura da soja, Araçatuba, SP, safra 2011/12.

\begin{tabular}{lll}
\hline Cultivar & sem N & com N \\
\hline P 98Y11 RR & $3025 \mathrm{~b}$ & $2904 \mathrm{ab}$ \\
CD 219 RR & $2228 \mathrm{~b}$ & $2998 \mathrm{ab}$ \\
M-Soy 7908 RR & $4840 \mathrm{Aa}$ & $3740 \mathrm{Bab}$ \\
BRS Valiosa RR & $2970 \mathrm{~b}$ & $2299 \mathrm{~b}$ \\
SYN 9078 RR & $2767 \mathrm{~b}$ & $2409 \mathrm{~b}$
\end{tabular}

DMS (1) 224,76

DMS (2)

155,97

Médias seguidas de mesma letra minúscula na coluna e maiúscula na linha não diferem entre si pelo teste de Tukey a $5 \%$ de probabilidade de erro.

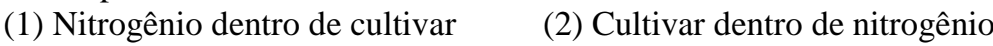

No segundo ano de estudo, as três doses de nitrogênio (30, 45 e $60 \mathrm{~kg} \mathrm{ha}^{-1}$ ) e as duas fontes utilizadas (ureia e nitrato de amônio) propiciaram diferenças somente em relação a altura de plantas, em Américo de campos, SP, sendo que o tratamento padrão (sem N), propiciou a maior altura de plantas, e diferiu do tratamento com $45 \mathrm{~kg} \mathrm{ha}^{-1}$ (Tabelas 7 e 8). Mesmo não diferindo estaticamente, a $5 \%$ de 
probabilidade, a produtividade de grãos da cultura da soja apresentou incrementos variando de 514 a 741 $\mathrm{kg} \mathrm{ha}^{-1}$, em Araçatuba, SP e de 442 a $788 \mathrm{~kg} \mathrm{ha}^{-1}$, em Américo de campos, SP (Tabelas 7 e 8), podendo ser a adubação nitrogenada uma ferramenta para aumento de produtividade de grãos neste sistema de produção, dependendo da relação custo/benefício, do fertilizante nitrogenado, pois, Mendes et al. (2008) obtiveram ganhos de produtividade, em média, de $216 \mathrm{~kg} \mathrm{ha}^{-1}$, mas citaram que a adubação nitrogenada tardia, no cultivo da soja com inoculação, em Latossolos do Cerrado, não se justifica economicamente, em nenhum dos sistemas de cultivo avaliados, direto e convencional, independentemente da fonte de $\mathrm{N}$ utilizada.

Tabela 7. Influência da aplicação de nitrogênio sobre a palhada de cana-de-açúcar, nas características fitotécnicas da cultivar de soja M-Soy 7908 RR, safra 2012/13, Araçatuba, SP.

\begin{tabular}{lcccc}
\hline $\begin{array}{l}\text { Doses de nitrogênio } \\
\left(\mathrm{kg} \mathrm{ha}^{-1}\right)\end{array}$ & $\begin{array}{c}\text { Altura de } \\
\text { inserção } \\
(\mathrm{m})\end{array}$ & $\begin{array}{c}\text { Altura de plantas } \\
(\mathrm{m})\end{array}$ & $\begin{array}{c}\text { Estande final } \\
\mathrm{ha}^{-1^{*}}\end{array}$ & $\begin{array}{c}\text { Produtividade } \\
\left(\mathrm{kg} \mathrm{ha}^{-1}\right)\end{array}$ \\
\hline 0 & 0,12 & 0,65 & 225183 & 3506 \\
30 (Nitrato de amônio) & 0,15 & 0,69 & 216294 & 4020 \\
60 (Nitrato de amônio) & 0,15 & 0,69 & 207405 & 4247 \\
45 (Ureia) & 0,16 & 0,68 & 200739 & 4247 \\
\hline DMS & 0,634 & 0,1097 & & 1490 \\
\hline CV $(\%)$ & 15,46 & 5,71 & & 13,15 \\
\hline
\end{tabular}

* Não se comparou as médias por variarem de acordo com a recomendação do detentor da cultivar.

Tabela 8. Influência da aplicação de nitrogênio sobre a palhada de cana-de-açúcar, nas características fitotécnicas da cultivar de soja SYN 9078 RR, safra 2012/13, Américo de Campos, SP.

\begin{tabular}{|c|c|c|c|c|c|}
\hline $\begin{array}{l}\text { Doses de nitrogênio } \\
\left(\mathrm{kg} \mathrm{ha}^{-1}\right)\end{array}$ & $\begin{array}{c}\text { Altura de } \\
\text { inserção } \\
\text { (m) }\end{array}$ & $\begin{array}{l}\text { Altura de } \\
\text { plantas } \\
\text { (m) }\end{array}$ & $\begin{array}{c}\text { Estande } \\
\text { final } \\
\mathrm{ha}^{-1^{*}}\end{array}$ & $\begin{array}{l}\text { Número de } \\
\text { vagens } \\
\text { planta }^{-1}\end{array}$ & $\begin{array}{l}\text { Produtividade } \\
\qquad\left(\mathrm{kg} \mathrm{ha}^{-1}\right)\end{array}$ \\
\hline 0 & 0,11 & $0,64 \quad \mathrm{a}$ & 272000 & 47 & 3022 \\
\hline 30 (Nitrato de amônio) & 0,10 & $0,59 \mathrm{ab}$ & 249333 & 56 & 3810 \\
\hline 60 (Nitrato de amônio) & 0,12 & $0,57 \quad a b$ & 254667 & 44 & 3605 \\
\hline 45 (Ureia) & 0,10 & 0,53 & 268667 & 41 & 3464 \\
\hline DMS & 0,0216 & 0,0911 & 59289 & 56,5941 & 2082 \\
\hline $\mathrm{CV}(\%)$ & 7,04 & 5,54 & 8,02 & 42,41 & 21,18 \\
\hline
\end{tabular}

Médias seguidas de mesma letra nas colunas não diferem entre si pelo teste de Tukey a 5\%.

* Não se comparou as médias por variarem de acordo com a recomendação do detentor da cultivar.

\section{CONCLUSÃO}

A utilização de ureia e de nitrato de amônio não influenciou a decomposição da palhada de canade-açúcar e não propiciaram incrementos significativos na produtividade de grãos das cultivares de soja avaliadas. 


\section{AGRADECIMENTOS}

Agradecemos a Fundação Agrisus - Agricultura Sustentável, pelo apoio financeiro ao projeto que originou este trabalho, nas duas safras.

\section{REFERÊNCIAS}

ABRAMO FILHO, J.et al. Resíduo da colheita mecanizada de cana crua. Álcool \& Açúcar, São Paulo, n. 67, p. 23-25, 1993.

AMADO, T. J. C.; MIELNICZUK, J.; AITA, C. Recomendação de adubação nitrogenada para o milho no RS e SC adaptada ao uso de culturas de coberturas do solo, sob sistema de plantio direto. Revista Brasileira de Ciência do Solo, Viçosa, v. 26, n. 1, p. 241-248, 2002.

ARATANI, R. G.et al. adubação nitrogenada em soja na implantação do sistema plantio direto.

Bioscience Journal, Uberlândia, v. 24, n. 3, p. 31-38, 2008.

ASSIS, E. P. M.et al. Efeito da aplicação de nitrogênio na atividade microbiana e na decomposição da palhada de sorgo em solo de cerrado sob plantio direto. Pesquisa Agropecuária Tropical, Goiânia, v. 33, n. 2, p. 107-112, 2003.

BOLONHEZI, D.et al. Plantio direto de cultivares de soja RR na renovação de cana em condição de Argissolo. In: REUNIÃO DE PESQUISA DE SOJA DA REGIÃO CENTRAL DO BRASIL, 30., 2008, Rio Verde. Resumos... Londrina: Embrapa Soja, 2008. p.45-47, 2008.

CIIAGRO - CENTRO INTEGRADO DE INFORMAÇÕES AGROMETEOROLÓGICAS. Resenha: Votuporanga no período de 01/11/2008 até 31/04/2010. São Paulo, 2013. Disponível em: <http://www.ciiagro.sp.gov.br/ciiagroonline/Listagens/Resenha/LResenhaLocal.asp>. Acesso em 20 mai. 2013.

ESTAT - Sistema para análises estatísticas. (V.2.0), Polo Computacional/Departamento de Ciências Exatas/UNESP-FCAV, Campus de Jaboticabal, Jaboticabal, SP [s.d.]. 1997.

CRISPINO, C. C.et al. Adubação Nitrogenada na Cultura da Soja. Comunicado Técnico, 75. Embrapa Soja: Londrina, 6 p., 2001.

KATTERER, T.et al. Temperature dependence of organic matter decomposition: a critical review using data analyzed with different models. Biology and Fertility of Soils, v. 27, n. 3, p. 258-262, 1998.

KUVA, M. A. Banco de sementes, fluxo de emergência e fitossociologia de comunidade de plantas daninhas em agroecossistema de cana. 2006. 105 f. Tese (Doutorado em Agronomia) - Faculdade de Ciências Agrárias e Veterinárias, Universidade Estadual Paulista, Jaboticabal.

LAMOND, R. E.; WESLEY, T. L. Informações Agronômicas, n. 95, 2001.

MASCARENHAS, H. A. A.et al. Efeito do nitrogênio residual da soja na produção de milho. In: Seminário Nacional de Pesquisa de Soja, I. Londrina, 1.978. Anais... Londrina, EMBRAPA/CNPSoja, 1978. p.307.

MENDES, I. C.et al. Adubação nitrogenada suplementar tardia em soja cultivada em Latossolos do Cerrado. Pesquisa Agropecuária Brasileira, Brasília, v. 43, n. 8, p. 1053-1060, 2008. 
OLIVEIRA, M. W.et al. Degradação da palhada de cana-de-açúcar. Scientia Agricola, Piracicaba, v. 56 n. 4, 1999.

RIPOLI, T. V.; MIALHE, L. G.; BRITO, J. O. Queima de canavial, o desperdício não mais admissível. Álcool \& Açúcar, São Paulo, v. 10, n. 54, p. 18-23, 1990.

SANTOS, L. P.et al. Adubação nitrogenada e molíbdica da cultura da soja em Viçosa e Coimbra, Minas Gerais. Revista Ceres, Viçosa, v.47, n. 269, p. 33-48, 2000.

STANFORD, G.; FRERE, M.H.; SHWANINGER, D.H. Temperature coefficient of soil nitrogen mineralization. Soil Science, v. 115, p. 321-323, 1973.

TIMOSSI, P. C.; DURIGAN, J. C. Manejo de convolvuláceas em dois cultivares de soja semeada diretamente sob palha residual de cana crua. Planta Daninha, Viçosa, v. 24, n. 1, p. 91-98, 2006.

TRIVELIN, P. C. O.et al. Utilização da soqueira de cana-de-açúcar de início de safra do nitrogênio da aquamônia ${ }^{15} \mathrm{~N}$ e ureia ${ }^{15} \mathrm{~N}$ aplicado ao solo em complemento a vinhaça. Pesquisa Agropecuária Brasileira, Brasília, v. 31, n. 2, p. 89-99, 1996.

TRIVELIN, P. C. O.; VICTORIA, R. L.; RODRIGUES, J. C. S. Aproveitamento por soqueira de cana-deaçúcar de final de safra do nitrogênio da aquamônia ${ }^{-15} \mathrm{~N}$ e ureia ${ }^{-15} \mathrm{~N}$ aplicado ao solo em complemento à vinhaça. Pesquisa Agropecuária Brasileira, Brasília, v. 30, n. 12, p. 1375-1385, 1995. 